\title{
HIGH-ORDER FINITE DIFFERENCE SCHEMES FOR SOLVING THE ADVECTION-DIFFUSION EQUATION
}

\author{
Murat Sari ${ }^{1}$, Gürhan Gürarslan ${ }^{2}$ and Asuman Zeytinoğlu ${ }^{3}$ \\ ${ }^{1}$ Department of Mathematics, Faculty of Art and Science, Pamukkale University, \\ Denizli 20070, Turkey.msari@pau.edu.tr \\ ${ }^{2}$ Department of Civil Engineering, Faculty of Engineering, Pamukkale University, \\ Denizli 20070, Turkey. \\ ${ }^{3}$ Department of Mathematics, Faculty of Art and Science, Süleyman Demirel \\ University, Isparta 32260, Turkey.
}

\begin{abstract}
Up to tenth-order finite difference schemes are proposed in this paper to solve one-dimensional advection-diffusion equation. The schemes based on high-order differences are presented using Taylor series expansion. To obtain the solutions, up to tenth-order finite difference schemes in space and a fourth-order Runge-Kutta scheme in time have been combined. The methods are implemented to solve two problems having exact solutions. Numerical experiments have been conducted to demonstrate the efficiency and high-order accuracy of the current methods. The techniques are seen to be very accurate in solving the advection-diffusion equation for $P e \leq 5$. The produced results are also seen to be more accurate than some available results given in the literature.
\end{abstract}

Key Words- Advection-Diffusion Equation, Contaminant Transport, High-order Finite Difference Schemes, Runge-Kutta.

\section{INTRODUCTION}

Advection-diffusion equation illustrates many quantities such as mass, heat, energy, velocity, vorticity, etc. The solutions of the equation model some of the phenomena such as the contaminant transport in groundwater, spread of pollutants in rivers, contaminant dispersion in shallow lakes and reservoirs etc. The slow progress has been made towards the analytical solutions of the advection-diffusion equation when initial and boundary conditions are intricate. Since many of the analytical solutions have not much easy use, many attempts have been carried out on developing the accurate numerical techniques. A number of numerical techniques have been recommended to illuminate physical phenomena described by the advection-diffusion equation in various fields of science. The difficulties arising in numerical solutions of the advection-diffusion equation results form the dominant advection that is for relatively high Peclect number. The one-dimensional advection-diffusion transport equation without the source terms has the following form:

$$
c_{t}+u c_{x}-D c_{x x}=0, a \leq x \leq b,
$$

where the subscripts $t$ and $x$ stand for differentiation with respect to time and space, respectively. Also $c, u$ and $D$ indicate concentration, velocity of water flow and the 
diffusion coefficient, respectively. Here $a$ and $b$ show the physical constants. The initial condition is

$$
c(x, 0)=f(x), a \leq x \leq b,
$$

and the boundary conditions are

$$
\begin{aligned}
& c(0, t)=g_{0}(t), 0<t \leq T, \\
& c(1, t)=g_{1}(t), 0<t \leq T,
\end{aligned}
$$

where $f, g_{0}$ and $g_{1}$ are prescribed functions whilst $u$ is the unknown function, concentration. Equation (1) describes two processes: advection and diffusion. Notice that $D>0$ and $u>0$ are considered to be positive constants quantifying the diffusion and advection processes, respectively.

To solve the advection-diffusion equation with the finite difference method, Noye and Tan [1] has used a weighted discretization with the modified equivalent partial differential equation. Soon after, the authors extended this scheme to solve twodimensional advection-diffusion equation [2]. However, solution of two- and threedimensional problems by using these methods is difficult since requirement of matrix inversions at each time step. The upwind scheme [3] and the flux-corrected scheme [4] are available for the solution of the depth-averaged form of the advection-diffusion equation. An alternative widely used approach is the split-operator approach $[5,6]$, in which the advection and diffusion terms are solved by two various numerical methods.

To solve the advection-diffusion equation accurately, various versions of the finite difference methods have been used in the literature [7-18]. Stability of various versions of the finite difference schemes for the advection-diffusion problems have been carried out in several studies in the literature [19-23]. The various forms of the finite difference schemes previously have been successfully described by means of using various combinations in getting the numerical solution of some problems represented by partial differential equations [24-29]. In this paper, highly accurate solutions of the advectiondiffusion equation are obtained using up to tenth-order finite difference schemes in space and a fourth-order Runga-Kutta (RK4) scheme in time. The numerical computations showed that the high-order schemes produce very accurate solutions in comparison with some previous works. Furthermore, these schemes can therefore be used for solving partial differential equations encountered in various fields of science.

\section{THE HIGH-ORDER SCHEMES}

Spatial derivatives are evaluated by various orders of finite difference schemes. The spatial derivative $c_{i}^{\prime}$ at point $i$ can be approximated by, $(R+L+1)$-point stencil, $(R+L)$-order finite-difference scheme as:

$$
c_{i}^{\prime}=\frac{1}{h} \sum_{j=-L}^{R} a_{j+L} c_{i+j}, 1 \leq i \leq N .
$$

where $h=x_{i+1}-x_{i}$ is the spacing of uniform mesh. The above formula involves $(R+L+1)$ constants, $a_{0}, a_{1}, a_{2} \ldots, a_{R+L}$ which need to be known at point $i . R$ and $L$ 
indicates number of points in the right hand side and the left hand side for the taken stencil, respectively. $R$ is equal to $L$ for the considered stencil at internal points but this is not the case for the boundary nodes. $N$ is the number of grid points. The coefficients $a_{j}$ were determined with Taylor series expansion of (5). Thus, the schemes using 7, 9 and 11 points, hereafter referred to as FD6, FD8 and FD10, are of order 6, 8 and 10 , respectively.

The coefficients $a_{j}$ for the first derivatives in the FD6, FD8 and FD10 schemes are given at internal nodes in Table 1.

Table 1. The coefficients $a_{j}$ for the first derivatives in the schemes at internal nodes

\begin{tabular}{cccccccccccc}
\hline Order & $a_{0}$ & $a_{1}$ & $a_{2}$ & $a_{3}$ & $a_{4}$ & $a_{5}$ & $a_{6}$ & $a_{7}$ & $a_{8}$ & $a_{9}$ & $a_{10}$ \\
\hline 6 & $\frac{-1}{60}$ & $\frac{9}{60}$ & $\frac{-45}{60}$ & 0 & $\frac{45}{60}$ & $\frac{-9}{60}$ & $\frac{1}{60}$ & -- & -- & -- & -- \\
8 & $\frac{3}{840}$ & $\frac{-32}{840}$ & $\frac{168}{840}$ & $\frac{-672}{840}$ & 0 & $\frac{672}{840}$ & $\frac{-168}{840}$ & $\frac{32}{840}$ & $\frac{-3}{840}$ & -- & -- \\
10 & $\frac{-2}{2520}$ & $\frac{25}{2520}$ & $\frac{-150}{2520}$ & $\frac{600}{2520}$ & $\frac{-2100}{2520}$ & 0 & $\frac{2100}{2520}$ & $\frac{-600}{2520}$ & $\frac{150}{2520}$ & $\frac{-25}{2520}$ & $\frac{2}{2520}$ \\
\hline
\end{tabular}

Table $2 \mathrm{a}$. The coefficients $a_{j}$ are given for the boundary nodes (1-5) for the relevant schemes

\begin{tabular}{|c|c|c|c|c|c|c|c|c|c|c|c|c|}
\hline Node & Order & $a_{0}$ & $a_{1}$ & $a_{2}$ & $a_{3}$ & $a_{4}$ & $a_{5}$ & $a_{6}$ & $a_{7}$ & $a_{8}$ & $a_{9}$ & $a_{10}$ \\
\hline \multirow{6}{*}{1} & \multirow{2}{*}{6} & -147 & 360 & -450 & 400 & -225 & 72 & -10 & \multirow{2}{*}{--} & \multirow{2}{*}{-- } & \multirow{2}{*}{--} & \multirow{2}{*}{--} \\
\hline & & $\overline{60}$ & $\overline{60}$ & $\overline{60}$ & $\overline{60}$ & $\overline{60}$ & $\overline{60}$ & $\overline{60}$ & & & & \\
\hline & \multirow{2}{*}{8} & -2283 & 6720 & -11760 & 15680 & -14700 & 9408 & -3920 & 960 & -105 & \multirow{2}{*}{-- } & \multirow{2}{*}{--} \\
\hline & & $\overline{840}$ & $\overline{840}$ & $\overline{840}$ & $\overline{840}$ & $\overline{840}$ & $\overline{840}$ & $\overline{840}$ & $\overline{840}$ & $\overline{840}$ & & \\
\hline & \multirow{2}{*}{10} & -7381 & 53200 & -56700 & 100800 & -132300 & 127008 & -88200 & 43200 & -14175 & 2800 & -252 \\
\hline & & $\overline{2520}$ & $\overline{2520}$ & $\overline{2520}$ & $\overline{2520}$ & $\overline{2520}$ & $\overline{2520}$ & 2520 & 2520 & 2520 & $\overline{2520}$ & $\overline{2520}$ \\
\hline \multirow{6}{*}{2} & \multirow{2}{*}{6} & -10 & -77 & 150 & -100 & 50 & -15 & 2 & \multirow{2}{*}{--} & \multirow{2}{*}{-- } & \multirow{2}{*}{-- } & \multirow{2}{*}{-- } \\
\hline & & $\overline{60}$ & $\overline{60}$ & $\overline{60}$ & $\overline{60}$ & $\overline{60}$ & $\overline{60}$ & $\overline{60}$ & & & & \\
\hline & \multirow{2}{*}{8} & -105 & -1338 & 2940 & -2940 & 2450 & -1470 & 588 & -140 & 15 & \multirow{2}{*}{-- } & \multirow{2}{*}{--} \\
\hline & & $\overline{840}$ & $\overline{840}$ & $\overline{840}$ & $\overline{840}$ & $\overline{840}$ & $\overline{840}$ & $\overline{840}$ & $\overline{840}$ & $\overline{840}$ & & \\
\hline & \multirow{2}{*}{10} & -252 & -4609 & 11340 & -15120 & 17640 & -15876 & 10584 & -5040 & 1620 & -315 & 28 \\
\hline & & $\overline{2520}$ & $\overline{2520}$ & $\overline{2520}$ & $\overline{2520}$ & $\overline{2520}$ & $\overline{2520}$ & $\overline{2520}$ & $\overline{2520}$ & $\overline{2520}$ & $\overline{2520}$ & $\overline{2520}$ \\
\hline \multirow{6}{*}{3} & \multirow{2}{*}{6} & 2 & -24 & -35 & 80 & -30 & 8 & -1 & \multirow{2}{*}{-- } & \multirow{2}{*}{-- } & \multirow{2}{*}{-- } & \multirow{2}{*}{--} \\
\hline & & $\overline{60}$ & $\overline{60}$ & $\overline{60}$ & $\overline{60}$ & $\overline{60}$ & $\overline{60}$ & $\overline{60}$ & & & & \\
\hline & \multirow{2}{*}{8} & 15 & -240 & -798 & 1680 & -1050 & 560 & -210 & 48 & -5 & \multirow{2}{*}{-- } & \multirow{2}{*}{--} \\
\hline & & $\overline{840}$ & $\overline{840}$ & $\overline{840}$ & $\overline{840}$ & $\overline{840}$ & $\overline{840}$ & $\overline{840}$ & $\overline{840}$ & $\overline{840}$ & & \\
\hline & \multirow{2}{*}{10} & 28 & -560 & -3609 & 6720 & -5880 & 4704 & -2940 & 1344 & -420 & 80 & -7 \\
\hline & & $\overline{2520}$ & 2520 & 2520 & $\overline{2520}$ & 2520 & $\overline{2520}$ & 2520 & $\overline{2520}$ & 2520 & $\overline{2520}$ & $\overline{2520}$ \\
\hline & 8 & -5 & 60 & -420 & -378 & 1050 & -420 & 140 & -30 & 3 & 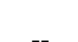 & 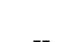 \\
\hline 4 & 8 & $\overline{840}$ & $\overline{840}$ & $\overline{840}$ & $\overline{840}$ & $\overline{840}$ & $\overline{840}$ & $\overline{840}$ & $\overline{840}$ & $\overline{840}$ & -- & -- \\
\hline 4 & 10 & -7 & 105 & -945 & -1914 & 4410 & -2646 & 1470 & -630 & 189 & -35 & 3 \\
\hline & 10 & $\overline{2520}$ & $\overline{2520}$ & $\overline{2520}$ & 2520 & $\overline{2520}$ & 2520 & $\overline{2520}$ & $\overline{2520}$ & $\overline{2520}$ & $\overline{2520}$ & $\overline{2520}$ \\
\hline 5 & 10 & 3 & -40 & 270 & -1440 & -924 & 3024 & -1260 & 480 & -135 & 24 & -2 \\
\hline 5 & 10 & $\overline{2520}$ & $\overline{2520}$ & $\overline{2520}$ & $\overline{2520}$ & $\overline{2520}$ & $\overline{2520}$ & $\overline{2520}$ & $\overline{2520}$ & $\overline{2520}$ & $\overline{2520}$ & $\overline{2520}$ \\
\hline
\end{tabular}


Table 2b.The coefficients $a_{j}$ are given for the boundary nodes ((N-4)-N) for the relevant schemes

\begin{tabular}{|c|c|c|c|c|c|c|c|c|c|c|c|c|}
\hline Node & Order & $a_{0}$ & $a_{1}$ & $a_{2}$ & $a_{3}$ & $a_{4}$ & $a_{5}$ & $a_{6}$ & $a_{7}$ & $a_{8}$ & $a_{9}$ & $a_{10}$ \\
\hline \multirow{2}{*}{$\mathrm{N}-4$} & \multirow{2}{*}{10} & 2 & -24 & 135 & -480 & 1260 & -3024 & 924 & 1440 & -270 & 40 & -3 \\
\hline & & $\overline{2520}$ & $\overline{2520}$ & $\overline{2520}$ & $\overline{2520}$ & $\overline{2520}$ & $\overline{2520}$ & $\overline{2520}$ & $\overline{2520}$ & $\overline{2520}$ & $\overline{2520}$ & $\overline{2520}$ \\
\hline \multirow{4}{*}{$\mathrm{N}-3$} & \multirow{2}{*}{8} & -3 & 30 & -140 & 420 & -1050 & 378 & 420 & -60 & 5 & . & 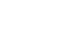 \\
\hline & & $\overline{840}$ & $\overline{840}$ & $\overline{840}$ & $\overline{840}$ & $\overline{840}$ & $\overline{840}$ & $\overline{840}$ & $\overline{840}$ & $\overline{840}$ & -- & -- \\
\hline & \multirow{2}{*}{10} & -3 & 35 & -189 & 630 & -1470 & 2646 & -4410 & 1914 & 945 & -105 & 7 \\
\hline & & 2520 & $\overline{2520}$ & 2520 & 2520 & 2520 & $\overline{2520}$ & 2520 & $\overline{2520}$ & $\overline{2520}$ & $\overline{2520}$ & 2520 \\
\hline \multirow{6}{*}{$\mathrm{N}-2$} & \multirow{2}{*}{6} & 1 & -8 & 30 & -80 & 35 & 24 & -2 & \multirow{2}{*}{--} & \multirow{2}{*}{--} & \multirow{2}{*}{--} & \multirow{2}{*}{-- } \\
\hline & & 60 & 60 & $\overline{60}$ & 60 & 60 & 60 & 60 & & & & \\
\hline & \multirow{2}{*}{8} & 5 & -48 & 210 & -560 & 1050 & -1680 & 798 & 240 & -15 & & \multirow{2}{*}{--} \\
\hline & & 840 & 840 & 840 & 840 & 840 & 840 & 840 & 840 & 840 & & \\
\hline & \multirow{2}{*}{10} & 7 & -80 & 420 & -1344 & 2940 & -4704 & 5880 & -6720 & 3069 & 560 & -28 \\
\hline & & 2520 & 2520 & 2520 & 2520 & 2520 & 2520 & 2520 & 2520 & 2520 & 2520 & 2520 \\
\hline \multirow{6}{*}{ N-1 } & \multirow{2}{*}{6} & -2 & 15 & -50 & 100 & -150 & 77 & 10 & & \multirow{2}{*}{--} & & \multirow{2}{*}{-- } \\
\hline & & 60 & 60 & 60 & 60 & 60 & 60 & 60 & & & & \\
\hline & \multirow{2}{*}{8} & -15 & 140 & -588 & 1470 & -2450 & 2940 & -2940 & 1338 & 105 & & \multirow{2}{*}{--} \\
\hline & & 840 & 840 & 840 & 840 & 840 & 840 & 840 & 840 & 840 & & \\
\hline & \multirow{2}{*}{10} & -28 & 315 & -1620 & 5040 & -10584 & 15876 & -17640 & 15120 & -11340 & 4609 & 252 \\
\hline & & 2520 & 2520 & 2520 & 2520 & 2520 & 2520 & 2520 & 2520 & 2520 & 2520 & 2520 \\
\hline \multirow{6}{*}{$\mathrm{N}$} & \multirow{2}{*}{6} & 10 & -72 & 225 & -400 & 450 & -360 & 147 & \multirow{2}{*}{--} & \multirow{2}{*}{--} & & _- \\
\hline & & 60 & 60 & 60 & 60 & 60 & 60 & 60 & & & & - \\
\hline & 8 & 105 & -960 & 3920 & -9408 & 14700 & -15680 & 11760 & -6720 & 2283 & & \\
\hline & 0 & $\overline{840}$ & $\overline{840}$ & $\overline{840}$ & $\overline{840}$ & $\overline{840}$ & $\begin{array}{c}840 \\
\end{array}$ & $\overline{840}$ & $\overline{840}$ & $\overline{840}$ & -- & -- \\
\hline & 10 & 252 & -2800 & 14175 & -43200 & 88200 & -127008 & 132300 & -100800 & 56700 & -25200 & 7381 \\
\hline & 10 & 2520 & 2520 & 2520 & 2520 & 2520 & 2520 & 2520 & 2520 & 2520 & 2520 & 2520 \\
\hline
\end{tabular}

Truncation error terms for the first-order derivative of the schemes are given by:

$$
T E=c_{i}^{\prime}-\frac{1}{h} \sum_{j=-L}^{R} a_{j+L} c_{i+j} .
$$

When the Taylor expansion of the second term in the RHS of the formula in above is used, the truncation terms of the schemes FD6, FD8, FD10 can be obtained as, respectively, $-0.007143 h^{6} c_{i}^{(7)}, 0.001587 h^{8} c_{i}^{(9)},-0.000361 h^{10} c_{i}^{(11)}$.

The coefficients for the first derivatives in the FD6, FD8 and FD10 schemes are given at boundary nodes in Table 2 .

First-order spatial derivative terms can be re-written into matrix form as follows:

$$
\mathbf{C}^{\prime}=\mathbf{A C} \text {. }
$$

The second-order spatial derivatives are obtained by applying the first-order operator twice, i.e.,

$$
\mathbf{C}^{\prime \prime}=\mathbf{A} \mathbf{C}^{\prime}
$$

where $\mathbf{C}=\left(c_{1}, c_{2}, \ldots, c_{N}\right)^{T}$.

For the approximate solutions of equation (1) with the boundary conditions (2) using the FD methods, first the interval $[a, b]$ is discretized such that $a=x_{1}<x_{2}<\ldots<x_{N}=b$ where $N$ is the number of grid points. After application of the 
FD techniques to equation (1), the equation can be reduced into a set of ordinary differential equations in time. Then the governing equation becomes

$$
\frac{d c_{i}}{d t}=P c_{i}
$$

where $P$ indicates a spatial differential operator. Each spatial derivative on the right hand side of equation (8) was computed using the present schemes and then the semidiscrete equation (8) was solved using the RK4 scheme, through the operations,

$$
\begin{aligned}
c_{i}^{(1)} & =c_{i}^{n}+\frac{1}{2} \Delta t P\left(c_{i}^{n}\right), \\
c_{i}^{(2)} & =c_{i}^{n}+\frac{1}{2} \Delta t P\left(c_{i}^{(1)}\right), \\
c_{i}^{(3)} & =c_{i}^{n}+\Delta t P\left(c_{i}^{(2)}\right), \\
c_{i}^{n+1} & =c_{i}^{n}+\frac{1}{6} \Delta t\left[P\left(c_{i}^{n}\right)+2 P\left(c_{i}^{(1)}\right)+2 P\left(c_{i}^{(2)}\right)+P\left(c_{i}^{(3)}\right)\right] .
\end{aligned}
$$

\section{NUMERICAL ILLUSTRATIONS}

To show the performance of the methods for the model problem, various error norms are reported. Let us consider the advection-diffusion equation (1) with the initial condition (2) and boundary conditions (3-4). The results are compared with the analytical and some numerical solutions. The numerical computations were performed using uniform grids. The computed solutions are shown in Tables 3-8.

An important non-dimensional parameter in numerical analysis is the Courant $(\mathrm{Cr})$ number. This parameter gives the fractional distance relative to the grid spacing travelled due to advection in a single time step $C r=(u \Delta t) / h$. It is possible to show using a Fourier error analysis that for a forward difference in time approximation (i.e. explicit), no matter what approximation is used for the spatial derivatives, that the transport equation is stable for values of the $C r<1$. This stability constraint for explicit transport equations states that one cannot advect the concentration more than one grid cell in a single time step.

The Peclet number is another important non-dimensional term which compares the characteristic time for dispersion and diffusion given a length scale with the characteristic time for advection. In numerical analysis, one normally refers to a grid Peclet number $P e=(u h) / D$, where $u$ is the velocity of water flow and the characteristic length scale is given by the grid spacing $h$. More details on the effects of the Courant and Peclet numbers on the results can be found in [30].

Two examples for which the exact solutions are known are now used to test the methods described for solving the advection-diffusion equation. Elapsed time $t$ is taken to be $1 \mathrm{~s}$ and $5 \mathrm{~s}$ in Example 1 and Example 2, respectively. The techniques are applied to solve (1)-(4) with $g_{0}(t), g_{1}(t)$ and $f(x)$ prescribed.

Example 1 [17, 31]. Consider (1)-(4) with

$$
f(x)=\exp \left(-\frac{(x+0.5)^{2}}{0.00125}\right), g_{0}(t)=\frac{0.025}{\sqrt{0.000625+0.02 t}} \exp \left(-\frac{(0.5-t)^{2}}{0.00125+0.04 t}\right)
$$




$$
g_{1}(t)=\frac{0.025}{\sqrt{0.000625+0.02 t}} \exp \left(-\frac{(1.5-t)^{2}}{0.00125+0.04 t}\right)
$$

for which the exact solution to the one-dimensional advection-diffusion in a region bounded by $0 \leq x \leq 1$ is taken from [17] and given as:

$$
c(x, t)=\frac{0.025}{\sqrt{0.000625+0.02 t}} \exp \left(-\frac{(x+0.5-t)^{2}}{0.00125+0.04 t}\right) .
$$

The parameters used are $D=0.01 \mathrm{~m}^{2} / \mathrm{s}$ and $u=1.0 \mathrm{~m} / \mathrm{s}$. The produced results and exact solutions are compared in Table 3 for the various values of the Courant number and for the different grid sizes. Both quantitative and qualitative agreement between the exact and the approximate solutions is excellent (see Tables 3-5, Figures 1a,b). Figures la,b show numerically calculated concentration profiles using the present approximations at grid Peclet numbers of 2 and 5, respectively, for the same Courant number $\mathrm{Cr}=0.2$ with various elapsed times. It has been seen that the approximated profiles are in very good agreement with their analytical counterparts.

For comparison purpose, for $P e=2, C r=0.2, \Delta t=0.004, h=0.02$ at $x=0.5$, absolute errors have also been computed and seen to be 4.03E-07, 1.42E-09 and 6.88E09 for the FD6, FD8 and FD10 respectively. It can be seen that these results are far better comparison to Dehghan's result [17] which is $1.80 \mathrm{E}-06$. Note that the same problem is solved in $[16,17]$ by using various forms of finite difference schemes. In the present model, using the present schemes, more accurate results are obtained in comparison with the corresponding references. As seen in Table 4, the high-order FD results are also compared with the results of Kadalbajoo and Arora [31] used the TaylorGalerkin B-spline finite element methods. It is seen that the present results are more accurate than their results. However, in order to improve the accuracy, the present work uses smaller time increment comparison to them.

The results of the three schemes for the equation are compared in Table 6 for this example. Table 5 shows that the accuracy of the solutions improves rapidly as the mesh size is reduced. All comparisons show that among the proposed schemes, the FD10 usually offer better results than the rest of two schemes. Therefore for the coming example, only the FD10 scheme is considered to observe the physical and mathematical behavior of the problem. 

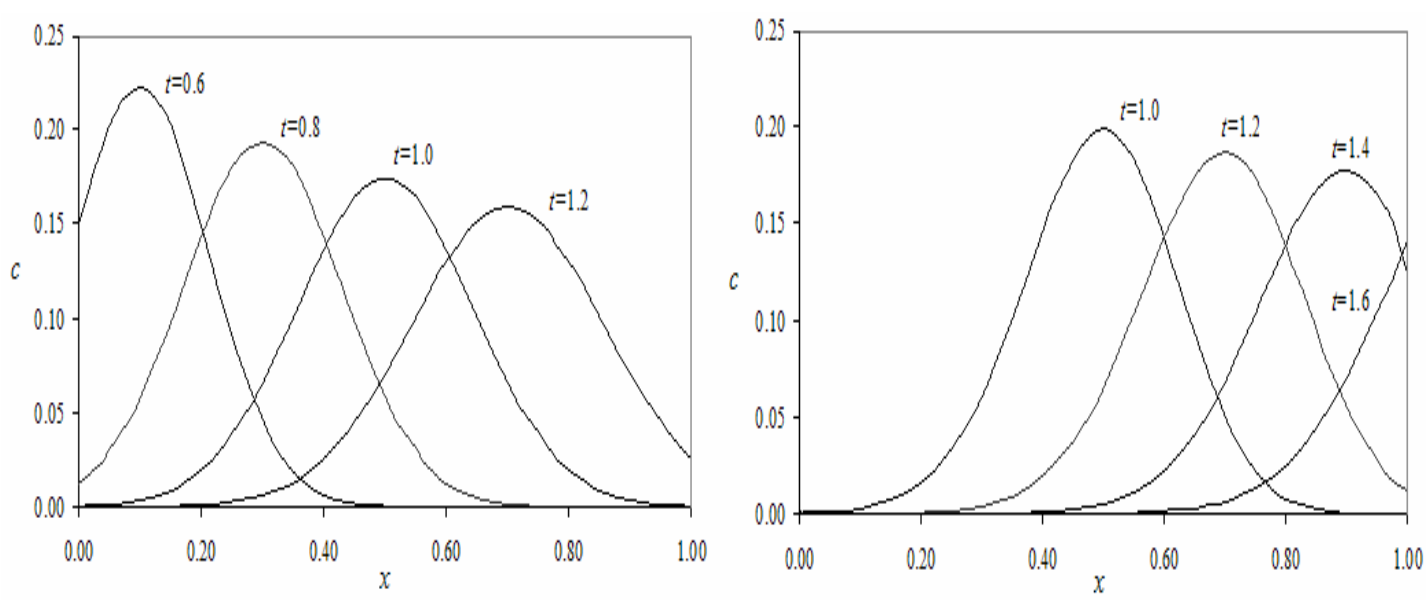

Figure 1. FD10 solution at various times in Example 1 for (a) $h=0.02,0 \leq x \leq 1$, $\Delta t=0.004, \quad u=1.0 \mathrm{~m} / \mathrm{s}, \quad D=0.01 \mathrm{~m}^{2} / \mathrm{s}, \quad C r=0.2, \quad P e=2,(\mathbf{b}) \quad h=0.025, \quad 0 \leq x \leq 1$, $\Delta t=0.01, u=1.0 \mathrm{~m} / \mathrm{s}, D=0.005 \mathrm{~m}^{2} / \mathrm{s}, C r=0.4, P e=5$.

Example 2 [13]. Let us consider equation (1) for $3.5 \leq x \leq 6.5, \quad u=0.8 \mathrm{~m} / \mathrm{s}$ and $D=0.005 \mathrm{~m}^{2} / \mathrm{s}$.

Then the exact solution to equation (1) as given by Noye and Tan [1] is

$$
c(x, t)=\frac{1}{\sqrt{4 t+1}} \exp \left[-\frac{(x-1-u t)^{2}}{D(4 t+1)}\right] .
$$

The initial and boundary conditions (2)-(4) are taken from the exact solution. The distribution of the Gaussian pulse is computed using the FD10 solutions as shown in Figure 2. As can be seen in Table 7 that the FD10 results in Example 2 is far more accurate comparison to Karahan's results [16]. In Table 4, various error norms of FD10 solutions for various values of $h, P e, \Delta t, C r$ with $x=5, t=5$ have also been presented in Example 2. FD10 solutions in addition to absolute and relative errors have also presented in Table 8 for various values of $x$ with $h=0.025, \Delta t=0.005, C r=0.16$ and $P e=4$.

\section{CONCLUSIONS}

In this work the advection-diffusion processes were dealt with using up to tenthorder finite difference schemes in space and the RK4 in time. The methods successfully worked to give very accurate solutions to these processes for $P e \leq 5$. The performance of the schemes for the considered problems was measured by calculating the various error indicators. The methods give convergent approximations, and handle the advectiondiffusion problems. The schemes based on high-order differences provide efficient and alternative methods for modelling the behaviour of the problem. Comparisons of the results with exact solutions showed that the present schemes are capable of solving the. For a further research, one can concentrate on solving the advection-diffusion problems using high Peclet numbers, $P e>5$, with high-order upwind schemes. Restrictions of the stability of the high-order FD schemes for the advection-diffusion problems will be analyzed in a future study in detail. 
Table 3. Numerical solutions for different schemes with $x=0.5, t=1.0, \mathrm{Pe}=2$ in Example 1.

\begin{tabular}{|c|c|c|c|c|c|c|c|c|c|c|}
\hline \multirow{2}{*}{$\Delta t$} & \multicolumn{5}{|c|}{$h=0.02, P e=2$} & \multicolumn{5}{|c|}{$h=0.01, P e=1$} \\
\hline & $\mathrm{Cr}$ & Exact & FD6 & FD8 & FD10 & $\mathrm{Cr}$ & Exact & FD6 & FD8 & FD10 \\
\hline 0.0005 & 0.025 & 0.17407766 & 0.17407682 & 0.17407772 & 0.17407764 & 0.050 & 0.17407766 & 0.17407765 & 0.17407766 & 0.17407766 \\
\hline 0.0010 & 0.050 & 0.17407766 & 0.17407689 & 0.17407772 & 0.17407765 & 0.100 & 0.17407766 & 0.17407765 & 0.17407766 & 0.17407766 \\
\hline 0.0020 & 0.100 & 0.17407766 & 0.17407702 & 0.17407769 & 0.17407765 & 0.200 & 0.17407766 & 0.17407765 & 0.17407766 & 0.17407766 \\
\hline 0.0033 & 0.167 & 0.17407766 & 0.17408557 & 0.17408607 & 0.17408605 & 0.333 & 0.17407766 & --- & --- & --- \\
\hline 0.0040 & 0.200 & 0.17407766 & 0.17407725 & 0.17407766 & 0.17407765 & 0.400 & 0.17407766 & --- & --- & -- \\
\hline 0.0080 & 0.400 & 0.17407766 & 0.17407757 & 0.17407761 & 0.17480605 & 0.800 & 0.17407766 & --- & -- & -- \\
\hline 0.0100 & 0.500 & 0.17407766 & 0.17407766 & --- & --- & 1.000 & 0.17407766 & --- & --- & --- \\
\hline
\end{tabular}

Table 4. A comparison of present solutions with the results of Kadalbajoo and Arora [31] at various nodal points with $h=0.01, t=1.0$ and $P e=1$ in Example 1 .

\begin{tabular}{|c|c|c|c|c|c|c|c|c|c|c|}
\hline \multirow{2}{*}{$x$} & \multirow{2}{*}{ Exact } & \multicolumn{3}{|c|}{$\Delta t=0.001, C r=0.1$} & \multicolumn{6}{|c|}{$\Delta t=0.01, C r=1$} \\
\hline & & FD6 & FD8 & FD10 & $\begin{array}{c}\text { TGBS1Q } \\
{[31]}\end{array}$ & $\begin{array}{c}\text { TGBS1L } \\
{[31]} \\
\end{array}$ & $\begin{array}{c}\text { TGBS2Q } \\
{[31]} \\
\end{array}$ & $\begin{array}{c}\text { TGBS2L } \\
{[31]} \\
\end{array}$ & $\begin{array}{c}\text { TGBS2HQ } \\
{[31]}\end{array}$ & $\begin{array}{c}\text { TGBS2HL } \\
{[31]} \\
\end{array}$ \\
\hline 0.1 & 0.0035992 & 0.0035992 & 0.0035992 & 0.0035992 & 0.0035860 & 0.0035872 & 0.0036345 & 0.0036360 & 0.0036055 & 0.0036070 \\
\hline 0.2 & 0.0196422 & 0.0196423 & 0.0196423 & 0.0196423 & 0.0196139 & 0.0196087 & 0.0196514 & 0.0196436 & 0.0196048 & 0.0195969 \\
\hline 0.3 & 0.0660098 & 0.0660099 & 0.0660099 & 0.0660099 & 0.0660910 & 0.0660729 & 0.0656778 & 0.0656522 & 0.0658887 & 0.0658624 \\
\hline 0.4 & 0.1366027 & 0.1366028 & 0.1366028 & 0.1366028 & 0.1368574 & 0.1368703 & 0.1361951 & 0.1362141 & 0.1366971 & 0.1367171 \\
\hline 0.5 & 0.1740776 & 0.1740777 & 0.1740777 & 0.1740777 & 0.1740807 & 0.1741277 & 0.1745342 & 0.1746041 & 0.1744042 & 0.1744743 \\
\hline 0.6 & 0.1366027 & 0.1366028 & 0.1366028 & 0.1366028 & 0.1362195 & 0.1362113 & 0.1373380 & 0.1373258 & 0.1365433 & 0.1365294 \\
\hline 0.7 & 0.0660098 & 0.0660099 & 0.0660099 & 0.0660099 & 0.0658153 & 0.0657761 & 0.0659965 & 0.0659361 & 0.0657310 & 0.0656721 \\
\hline 0.8 & 0.0196422 & 0.0196423 & 0.0196423 & 0.0196423 & 0.0197571 & 0.0197514 & 0.0193274 & 0.0193197 & 0.0196024 & 0.0195950 \\
\hline 0.9 & 0.0035992 & 0.0035992 & 0.0035992 & 0.0035992 & 0.0037190 & 0.0037288 & 0.0034599 & 0.0034754 & 0.0036699 & 0.0036847 \\
\hline
\end{tabular}


Table 5. Different error norms for various values of $C r$ and $\Delta t$ with ( $x=0.5$ for absolute and relative errors), $t=1.0, \mathrm{Pe}=2$ in Example 1.

\begin{tabular}{|c|c|c|c|c|c|c|c|c|c|c|c|}
\hline \multirow{2}{*}{ Scheme } & \multirow{2}{*}{$\Delta t$} & \multicolumn{5}{|c|}{$h=0.02, P e=2$} & \multicolumn{5}{|c|}{$h=0.01, P e=1$} \\
\hline & & $\mathrm{Cr}$ & $\begin{array}{l}\text { Absolute } \\
\text { error }\end{array}$ & $\begin{array}{l}\text { Relative } \\
\text { error }\end{array}$ & $L_{2}$ & $L_{\infty}$ & $\mathrm{Cr}$ & $\begin{array}{l}\text { Absolute } \\
\text { error }\end{array}$ & $\begin{array}{l}\text { Relative } \\
\text { error }\end{array}$ & $L_{2}$ & $L_{\infty}$ \\
\hline \multirow[t]{7}{*}{ FD6 } & 0.0005 & 0.025 & $8.40 \mathrm{E}-07$ & 4.83E-06 & $6.40 \mathrm{E}-07$ & $1.48 \mathrm{E}-06$ & 0.050 & $6.66 \mathrm{E}-09$ & $3.82 \mathrm{E}-08$ & $8.42 \mathrm{E}-09$ & 2.02E-08 \\
\hline & 0.0010 & 0.050 & $7.68 \mathrm{E}-07$ & 4.41E-06 & $6.08 \mathrm{E}-07$ & $1.42 \mathrm{E}-06$ & 0.100 & $5.80 \mathrm{E}-09$ & 3.33E-08 & 7.71E-09 & $1.86 \mathrm{E}-08$ \\
\hline & 0.0020 & 0.100 & $6.34 \mathrm{E}-07$ & $3.64 \mathrm{E}-06$ & $5.51 \mathrm{E}-07$ & $1.31 \mathrm{E}-06$ & 0.200 & 4.45E-09 & $2.56 \mathrm{E}-08$ & $6.60 \mathrm{E}-08$ & $1.61 \mathrm{E}-08$ \\
\hline & 0.0033 & 0.167 & 7.92E-06 & 4.55E-05 & 4.31E-05 & $7.43 \mathrm{E}-05$ & 0.333 & $9.09 \mathrm{E}-06$ & $5.22 \mathrm{E}-05$ & ---- & ---- \\
\hline & 0.0040 & 0.200 & 4.03E-07 & 2.32E-06 & 4.57E-07 & $1.11 \mathrm{E}-06$ & 0.400 & ---- & ---- & ---- & ---- \\
\hline & 0.0080 & 0.400 & 8.62E-08 & 4.95E-07 & $3.46 \mathrm{E}-07$ & $8.58 \mathrm{E}-07$ & 0.800 & ---- & --- & ---- & ---- \\
\hline & 0.0100 & 0.500 & 7.37E-09 & 4.23E-08 & $4.76 \mathrm{E}-05$ & 3.33E-04 & 1.000 & --- & --- & --- & --- \\
\hline \multirow[t]{7}{*}{ FD8 } & 0.0005 & 0.025 & 7.37E-08 & 4.23E-07 & $6.68 \mathrm{E}-08$ & $8.25 \mathrm{E}-08$ & 0.050 & $2.42 \mathrm{E}-11$ & $1.39 \mathrm{E}-10$ & $3.29 \mathrm{E}-11$ & $7.58 \mathrm{E}-11$ \\
\hline & 0.0010 & 0.050 & $6.15 \mathrm{E}-08$ & $3.53 \mathrm{E}-07$ & $3.17 \mathrm{E}-08$ & 7.08E-08 & 0.100 & $2.18 \mathrm{E}-11$ & $1.25 \mathrm{E}-10$ & $4.71 \mathrm{E}-11$ & $1.16 \mathrm{E}-10$ \\
\hline & 0.0020 & 0.100 & $3.90 \mathrm{E}-08$ & $2.24 \mathrm{E}-07$ & $2.27 \mathrm{E}-08$ & 4.94E-08 & 0.200 & $8.51 \mathrm{E}-11$ & $4.89 \mathrm{E}-10$ & $8.03 \mathrm{E}-11$ & $1.91 \mathrm{E}-10$ \\
\hline & 0.0033 & 0.167 & $8.41 \mathrm{E}-06$ & 4.83E-05 & 4.30E-05 & 7.37E-05 & 0.333 & ---- & ---- & ---- & ---- \\
\hline & 0.0040 & 0.200 & $1.42 \mathrm{E}-09$ & 8.17E-09 & $1.32 \mathrm{E}-08$ & $3.12 \mathrm{E}-08$ & 0.400 & ---- & ---- & ---- & ---- \\
\hline & 0.0080 & 0.400 & 4.13E-08 & $3.37 \mathrm{E}-07$ & 2.20E-08 & 4.88E-08 & 0.800 & ---- & ---- & ---- & ---- \\
\hline & 0.0100 & 0.500 & ---- & ---- & ---- & ---- & 1.000 & ---- & ---- & ---- & ---- \\
\hline \multirow[t]{7}{*}{ FD10 } & 0.0005 & 0.025 & $1.18 \mathrm{E}-08$ & $6.76 \mathrm{E}-08$ & 6.67E-09 & $1.51 \mathrm{E}-08$ & 0.050 & $4.50 \mathrm{E}-12$ & $2.58 \mathrm{E}-11$ & $2.39 \mathrm{E}-12$ & $5.40 \mathrm{E}-12$ \\
\hline & 0.0010 & 0.050 & $1.00 \mathrm{E}-08$ & 5.77E-08 & $5.63 \mathrm{E}-09$ & $1.27 \mathrm{E}-08$ & 0.100 & $1.74 \mathrm{E}-12$ & $9.97 \mathrm{E}-12$ & $1.09 \mathrm{E}-12$ & $2.49 \mathrm{E}-12$ \\
\hline & 0.0020 & 0.100 & $6.88 \mathrm{E}-09$ & $3.95 \mathrm{E}-08$ & $3.76 \mathrm{E}-09$ & 8.49E-09 & 0.200 & $5.15 \mathrm{E}-12$ & $2.96 \mathrm{E}-11$ & $2.46 \mathrm{E}-12$ & $5.83 \mathrm{E}-12$ \\
\hline & 0.0033 & 0.167 & $8.40 \mathrm{E}-06$ & 4.82E-05 & 4.30E-05 & 7.37E-05 & 0.333 & ---- & ---- & ---- & ---- \\
\hline & 0.0040 & 0.200 & $1.58 \mathrm{E}-09$ & $9.08 \mathrm{E}-09$ & $7.90 \mathrm{E}-10$ & $1.61 \mathrm{E}-09$ & 0.400 & ---- & ---- & ---- & ---- \\
\hline & 0.0080 & 0.400 & $5.72 \mathrm{E}-03$ & $3.28 \mathrm{E}-02$ & ---- & ---- & 0.800 & ---- & ---- & ---- & ---- \\
\hline & 0.0100 & 0.500 & ---- & ---- & ---- & ---- & 1.000 & ---- & ---- & ---- & ---- \\
\hline
\end{tabular}

Table 6. A comparison of analytical and numerical solutions for various values of $x$ with $h=0.02, \Delta t=0.004, C r=0.2$ and $P e=2$ in Example 1 .

\begin{tabular}{cccccccc}
\hline \multirow{2}{*}{$x$} & \multirow{2}{*}{ Exact } & \multicolumn{2}{c}{ FD6 } & \multicolumn{2}{c}{ FD8 } & \multicolumn{2}{c}{ FD10 } \\
\cline { 3 - 8 } & Results & $\begin{array}{c}\text { Absolute } \\
\text { errors }\end{array}$ & Results & $\begin{array}{c}\text { Absolute } \\
\text { errors }\end{array}$ & Results & $\begin{array}{c}\text { Absolute } \\
\text { errors }\end{array}$ \\
\hline 0.10 & 0.00359920727 & 0.00359921813 & $1.09 \mathrm{E}-08$ & 0.00359920589 & $1.38 \mathrm{E}-09$ & 0.00359920768 & $4.05 \mathrm{E}-10$ \\
0.20 & 0.01964225900 & 0.01964209009 & $1.69 \mathrm{E}-07$ & 0.01964226493 & $5.93 \mathrm{E}-09$ & 0.01964225790 & $1.10 \mathrm{E}-09$ \\
0.30 & 0.06600988665 & 0.06600982836 & $5.83 \mathrm{E}-08$ & 0.06600987396 & $1.27 \mathrm{E}-08$ & 0.06600988736 & $7.14 \mathrm{E}-10$ \\
0.40 & 0.13660277419 & 0.13660355137 & $7.78 \mathrm{E}-07$ & 0.13660278944 & $1.52 \mathrm{E}-08$ & 0.13660277500 & $8.09 \mathrm{E}-10$ \\
0.50 & 0.17407765596 & 0.17407725278 & $4.03 \mathrm{E}-07$ & 0.17407765738 & $1.42 \mathrm{E}-09$ & 0.17407765437 & $1.58 \mathrm{E}-09$ \\
0.60 & 0.13660277419 & 0.13660192973 & $8.44 \mathrm{E}-07$ & 0.13660274865 & $2.55 \mathrm{E}-08$ & 0.13660277488 & $6.82 \mathrm{E}-10$ \\
0.70 & 0.06600988665 & 0.06601059056 & $7.04 \mathrm{E}-07$ & 0.06600991054 & $2.39 \mathrm{E}-08$ & 0.06600988717 & $5.19 \mathrm{E}-10$ \\
0.80 & 0.01964225900 & 0.01964248474 & $2.26 \mathrm{E}-07$ & 0.01964225650 & $2.49 \mathrm{E}-09$ & 0.01964225832 & $6.73 \mathrm{E}-10$ \\
0.90 & 0.00359920727 & 0.00359895542 & $2.52 \mathrm{E}-07$ & 0.00359920059 & $6.68 \mathrm{E}-09$ & 0.00359920743 & $1.54 \mathrm{E}-10$ \\
\hline
\end{tabular}




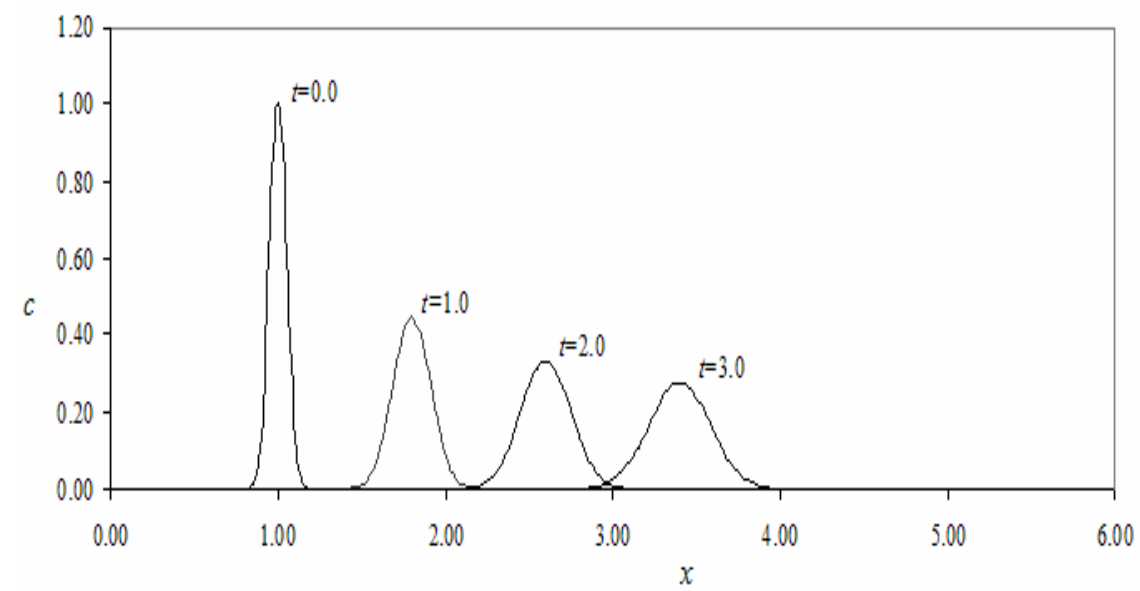

Figure 2. FD10 solutions for transport of one-dimensional Gaussian pulse at various times with the parameters $h=0.025,0 \leq x \leq 6, \Delta t=0.005, u=0.8 \mathrm{~m} / \mathrm{s}, D=0.005 \mathrm{~m}^{2} / \mathrm{s}$, $\mathrm{Cr}=0.16, \mathrm{Pe}=4$ in Example 2.

Table 7. Different error values of FD10 solutions for various values of $h, P e, \Delta t, C r$ with $x=5, t=5$ in Example 2.

\begin{tabular}{|c|c|c|c|c|c|c|c|c|c|}
\hline \multirow{2}{*}{$h, P e$} & \multirow{2}{*}{$\Delta t$} & \multirow{2}{*}{ Exact } & \multirow{2}{*}{$\mathrm{Cr}$} & \multirow{2}{*}{ FD10 } & \multicolumn{2}{|c|}{ Absolute error } & \multirow{2}{*}{$\begin{array}{l}\text { Relative } \\
\text { error }\end{array}$} & \multirow{2}{*}{$L_{2}$} & \multirow{2}{*}{$L_{\infty}$} \\
\hline & & & & & Ref.[16] & Present & & & \\
\hline \multirow{7}{*}{$\begin{array}{c}h=0.025, \\
P e=4\end{array}$} & 0.0005 & 0.21821789 & 0.016 & 0.21821789 & $9.13 \mathrm{E}-04$ & $1.74 \mathrm{E}-09$ & 7.97E-09 & $5.78 \mathrm{E}-10$ & $1.75 \mathrm{E}-09$ \\
\hline & 0.0010 & 0.21821789 & 0.032 & 0.21821789 & 9.31E-04 & $1.64 \mathrm{E}-09$ & 7.50E-09 & $5.44 \mathrm{E}-10$ & $1.64 \mathrm{E}-09$ \\
\hline & 0.0020 & 0.21821789 & 0.064 & 0.21821789 & $9.73 \mathrm{E}-04$ & $1.44 \mathrm{E}-09$ & $6.60 \mathrm{E}-09$ & 4.79E-10 & 1.44E-09 \\
\hline & 0.0025 & 0.21821789 & 0.080 & 0.21821789 & $9.96 \mathrm{E}-04$ & $1.35 \mathrm{E}-09$ & $6.17 \mathrm{E}-09$ & $4.48 \mathrm{E}-10$ & $1.35 \mathrm{E}-09$ \\
\hline & 0.0050 & 0.21821789 & 0.160 & 0.21821789 & $1.13 \mathrm{E}-03$ & 8.83E-10 & 4.05E-09 & $3.00 \mathrm{E}-10$ & $9.10 \mathrm{E}-10$ \\
\hline & 0.0100 & 0.21821789 & 0.320 & 0.21821789 & $1.47 \mathrm{E}-03$ & 7.55E-10 & $3.46 \mathrm{E}-09$ & $2.58 \mathrm{E}-10$ & 7.55E-10 \\
\hline & 0.0200 & 0.21821789 & 0.640 & ---- & $2.26 \mathrm{E}-03$ & ---- & --- & ---- & ---- \\
\hline \multirow{7}{*}{$\begin{array}{c}h=0.0125 \\
P e=2\end{array}$} & 0.0005 & 0.21821789 & 0.032 & 0.21821789 & $8.59 \mathrm{E}-05$ & $6.06 \mathrm{E}-13$ & $2.78 \mathrm{E}-12$ & $3.00 \mathrm{E}-13$ & $9.13 \mathrm{E}-13$ \\
\hline & 0.0010 & 0.21821789 & 0.064 & 0.21821789 & $9.53 \mathrm{E}-05$ & $4.48 \mathrm{E}-13$ & $2.05 \mathrm{E}-12$ & $2.64 \mathrm{E}-13$ & $8.57 \mathrm{E}-13$ \\
\hline & 0.0020 & 0.21821789 & 0.128 & 0.21821789 & $1.16 \mathrm{E}-04$ & 3.62E-14 & $1.66 \mathrm{E}-13$ & $1.56 \mathrm{E}-13$ & $5.72 \mathrm{E}-13$ \\
\hline & 0.0025 & 0.21821789 & 0.160 & 0.21821789 & $1.26 \mathrm{E}-04$ & $7.51 \mathrm{E}-13$ & $3.44 \mathrm{E}-12$ & $2.65 \mathrm{E}-13$ & $8.08 \mathrm{E}-13$ \\
\hline & 0.0050 & 0.21821789 & 0.320 & 0.21821789 & $1.85 \mathrm{E}-04$ & $3.09 \mathrm{E}-11$ & $1.41 \mathrm{E}-10$ & $1.02 \mathrm{E}-11$ & 3.23E-11 \\
\hline & 0.0100 & 0.21821789 & 0.640 & --- & $3.27 \mathrm{E}-04$ & --- & --- & --- & ---- \\
\hline & 0.0200 & 0.21821789 & 1.280 & ---- & 0.217533 & ---- & ---- & ---- & ---- \\
\hline
\end{tabular}

Table 8 . FD10 solutions in addition to absolute and relative errors for various values of $x$ with $h=0.025, \Delta t=0.005, C r=0.16$ and $P e=4$.

\begin{tabular}{ccccc}
\hline$x$ & Exact & FD10 & Absolute errors & Relative errors \\
\hline 3.50 & 0.0000000 & 0.0000000 & $3.13 \mathrm{E}-09$ & $1.60 \mathrm{E}-12$ \\
4.00 & 0.0000159 & 0.0000159 & $5.82 \mathrm{E}-09$ & $4.55 \mathrm{E}-07$ \\
4.50 & 0.0201770 & 0.0201770 & $1.56 \mathrm{E}-08$ & $1.32 \mathrm{E}-08$ \\
5.00 & 0.2182179 & 0.2182179 & $2.31 \mathrm{E}-08$ & $4.05 \mathrm{E}-09$ \\
5.50 & 0.0201770 & 0.0201770 & $2.89 \mathrm{E}-08$ & $9.56 \mathrm{E}-09$ \\
6.00 & 0.0000159 & 0.0000159 & $1.00 \mathrm{E}-09$ & $4.77 \mathrm{E}-07$ \\
6.50 & 0.0000000 & 0.0000000 & $5.22 \mathrm{E}-13$ & $1.30 \mathrm{E}-12$ \\
\hline
\end{tabular}




\section{REFERENCES}

1. B. J. Noye and H. H. Tan, A third-order semi-implicit finite difference method for solving the one-dimensional convection-diffusion equation, International Journal for Numerical Methods in Engineering, 26, 1615-29, 1988.

2. B. J. Noye and H. H. Tan, Finite difference methods for the two-dimensional advection diffusion equation, International Journal for Numerical Methods in Fluids, 9, 75-98, 1989.

3. D. B. Spalding, A novel finite difference formulation for differential expression involving both first and second derivatives, International Journal for Numerical Methods in Fluids, 4, 551-559, 1972.

4. J. B. Boris and D. L. Book, Flux corrected for transport algorithm that works, Journal of Computational Physics, 11, 38-69, 1973.

5. Y. S. Li and C. P. Chen, An efficient split operator scheme for 2D advection diffusion equation using finite elements and characteristics, Applied Mathematical Modelling, 13, 248-253, 1989.

6. R. J. Sobey, Fractional step algorithm for estuarine mass transport, International Journal for Numerical Methods in Fluids, 3, 567-581, 1983.

7. M. K. Patel, N. C. Markatos and M. Cross, A critical evaluation of seven discretisation schemes for convection-diffusion equation, International Journal for Numerical Methods in Fluids, 5, 225-244, 1985.

8. B. P. Leonard, Simple high accuracy resolution program for convective modeling of discontinuities, International Journal for Numerical Methods in Fluids, 8, 1291-1318, 1988.

9. J. A. Kaandrop, C. P. Lowe, D. Frenkel and P. M. A. Sloot, Effect of nutrient diffusion and flow on coral morphology, Physical Review Letters, 77, 2328-2331, 1996.

10. P. B. Warren, Electroviscous transport problems via Lattice-Boltzmann, International Journal of Modern Physics C, 8, 889-898, 1997.

11. R. M. H. Merks, A. G. Hoekstra and P. M. A. Sloot, The moment propagation method for advection-diffusion in the Lattice Boltzmann method: validation and Peclet number limits, Journal of Computational Physics, 183, 563-576, 2002.

12. B. P. Sommeijer and J. Kok, Implementation and performance of the time integration of a 3D numerical transport model, International Journal for Numerical Methods in Fluids, 21, 349-367, 1995.

13. S. Sankaranarayanan, N. J. Shankar and H. F. Cheong, Three-dimensional finite difference model for transport of conservative pollutants, Ocean Engineering, 25, 425442, 1998.

14. K. Huang, J. Simunek and M. T. H. Genuchten, A third-order numerical scheme with upwind weighting for solving the solute transport equation, International Journal for Numerical Methods in Engineering, 40, 1623-37, 1997.

15. C. Zoppou, S. Roberts and R. J. Renka, Exponential spline interpolation in characteristic based scheme for solving the advective-diffusion equation, International Journal for Numerical Methods in Fluids, 33, 429-452, 2000.

16. H. Karahan, A third-order upwind scheme for the advection-diffusion equation using spreadsheets, Advances in Engineering Software, 38, 688-697, 2007. 
17. M. Dehghan, Weighted finite difference techniques for the one-dimensional advection-diffusion equation, Applied Mathematics and Computation, 147, 307-319, 2004.

18. I. Dağ, D. Irk and M. Tombul, Least-squares finite element method for the advection-diffusion equation, Applied Mathematics and Computation, 173, 554-565, 2006.

19. A. C. Hindmarsh, P. M. Gresho and D. F. Griffiths, The stability of explicit Euler time-integration for certain finite difference approximations of the multi-dimensional advection-diffusion equation, International Journal for Numerical Methods in Fluids, 4, 853-897, 1984.

20. A. Rigal, Numerical analysis of two-level finite difference schemes for unsteady diffusion-convection problems, International Journal for Numerical Methods in Engineering, 28, 1001-1021, 1989.

21. A. Rigal, Stability analysis of finite difference schemes for two-dimensional advection-diffusion problems, International Journal for Numerical Methods in Fluids, 13, 579-597, 1991.

22. P. Wesseling, Von Neumann stability conditions for the convection-diffusion equation, IMA Journal of Numerical Analysis, 16, 583-598, 1996.

23. J. M. C. Pereira and J. C. F. Pereira, Fourier analysis of several finite difference schemes for the one-dimensional unsteady convection-diffusion equation, International Journal for Numerical Methods in Fluids, 36, 417-439, 2001.

24. M. Sari and G. Gürarslan, A sixth-order compact finite difference scheme to the numerical solutions of Burgers' equation, Applied Mathematics and Computation, 208, 475-483, 2009.

25. M. Sari, G. Gürarslan and I. Dağ, A compact finite difference method for the solution of the generalized Burgers-Fisher equation, Numerical Methods for Partial Differential Equations, (2009), doi: 10.1002/num.20421.

26. S. Karaa and J. Zhang, High order ADI method for solving unsteady convectiondiffusion problems, Journal of Computational Physics, 198, 1-9, 2004.

27. M. Sari, Solution of the porous media equation by a compact finite difference method, Mathematical Problems in Engineering, 2009, 2009, Article ID 912541.

28. J. Li, High-order finite difference schemes for differential equations containing higher derivatives, Applied Mathematics and Computation, 171, 1157-1176, 2005.

29. M. Sari and G. Gürarslan, A sixth-order compact finite difference method for the one-dimensional sine-Gordon equation, Communications in Numerical Methods in Engineering (accepted).

30. C. I. Steefel and K. T. B. MacQuarrie, Approaches to modeling reactive transport in porous media. In Reactive Transport in Porous Media (Lichtner PC, Steefel CI, Oelkers EH eds.), Reviews in Mineralogy 34, 83-125, 1996.

31. M. K. Kadalbajoo and P. Arora, Taylor-Galerkin B-spline finite element method for the one-dimensional advection-diffusion equation, Numerical Methods for Partial Differential Equations (2009), doi: 10.1002/num.20488. 